\title{
Assessing the risk of recurrent venous thromboembolism - a practical approach
}

This article was published in the following Dove Press journal:

Vascular Health and Risk Management

17 August 2015

Number of times this article has been viewed

\author{
Jennifer Fahrni' \\ Marc Husmann² \\ Silvia B Gretener ${ }^{3}$ \\ Hong $\mathrm{H} \mathrm{Keo'}^{\prime}$ \\ 'Division of Angiology, Medical \\ University Clinic, Kantonsspital \\ Aarau AG, Aarau, Switzerland; ${ }^{2}$ Clinic \\ for Angiology, University Hospital, \\ University of Zurich, Zürich, \\ Switzerland; ${ }^{3}$ Clinic for Angiology \\ Oberaargau, Langenthal, Switzerland
}

Correspondence: Hong $\mathrm{H} \mathrm{KeO}$

Division of Angiology, Medical

University Clinic, Kantonsspital Aarau

AG, Tellstrasse, Haus 6, 5000 Aarau,

Switzerland

$\mathrm{Tel}+4 \mid 628386440$

Fax $+4 \mid 628384710$

Email keoxx006@umn.edu

\begin{abstract}
Recurrent venous thromboembolism (VTE) is associated with increased morbidity and mortality. This risk is lowered by anticoagulation, with a large effect in the initial phase following the venous thromboembolic event, and with a smaller effect in terms of secondary prevention of recurrence when extended anticoagulation is performed. On the other hand, extended anticoagulation is associated with an increased risk of major bleeding and thus leads to morbidity and mortality. Therefore, it is necessary to assess the risk of recurrence for VTE on an individual basis, and a recommendation for secondary prophylaxis should be specifically based on risk calculation of recurrence of VTE and bleeding. In this review, we provide a comprehensive summary of relevant risk factors for recurrent VTE and a practical approach for assessing the risk of recurrence in daily practice.
\end{abstract}

Keywords: thrombosis, hemorrhage, risk assessment

\section{Venous thromboembolism}

Venous thromboembolism (VTE), which includes deep vein thrombosis (DVT) and pulmonary embolism (PE), is a common disease and presents a major health problem. In the general population, the absolute risk of any kind of VTE is $0.1 \%-0.2 \%$ per year, and it increases with age. The risk of recurrence after a first episode of VTE is $5 \%-7 \%$ per year, and it is more than 50 times higher than in patients without previous VTE. ${ }^{1}$ Patients with incident VTE are always at risk for recurrence, regardless of the time elapsed since the first event. However, the risk of recurrence does decrease over time. ${ }^{2,3}$ It is important to make a distinction between provoked and unprovoked VTE, as the risk of recurrence differs. The adjective "provoked" signifies the occurrence of VTE in the presence of an acquired transient risk factor such as recent surgery or pregnancy; or a persistent risk factor, such as cancer. When no clinical risk factor can be identified, the VTE is called unprovoked or idiopathic. ${ }^{4}$

Continued anticoagulation after the initial VTE will reduce the risk of recurrence, but must be carefully weighed against the risk of treatment, namely anticoagulantrelated bleeding. Thus, it is very important to assess the risk of recurrence in each individual patient as to be able to adequately weigh this risk against the risks of longterm anticoagulation. Estimating the risk of recurrent VTE is complex and requires consideration of relevant risk factors for recurrent VTE.

The optimal duration of anticoagulation after VTE has been debated for years. Based on a number of studies and meta-analyses, the current American College of Chest Physicians (ACCP) Guidelines, published in 2012, ${ }^{5}$ recommend the following (Table 1). 
Table I Duration of anticoagulation in patients with acute DVT of the leg ${ }^{5}$

\begin{tabular}{|c|c|c|}
\hline Type of VTE & Duration of treatment & Recommendation \\
\hline Provoked isolated distal DVT & 3 months $^{a}$ & Grade IB \\
\hline \multirow[t]{4}{*}{ Unprovoked isolated distal DVT } & 3 months, ${ }^{a}$ then evaluation of risk-benefit ratio & Grade IB \\
\hline & of extended therapy & \\
\hline & For low or moderate bleeding risk $\rightarrow 3$ months & Grade 2B \\
\hline & For high bleeding risk $\rightarrow 3$ months & Grade IB \\
\hline Provoked proximal DVT & 3 months & Grade IB \\
\hline \multirow[t]{4}{*}{ Unprovoked proximal DVT } & At least 3 months, then evaluation of risk-benefit & Grade IB \\
\hline & ratio of extended therapy & \\
\hline & $\begin{array}{l}\text { For low or moderate bleeding risk } \rightarrow \text { extended } \\
\text { anticoagulant therapy }\end{array}$ & Grade 2B \\
\hline & For high bleeding risk $\rightarrow 3$ months & Grade IB \\
\hline \multirow[t]{3}{*}{ Second unprovoked DVT } & $\begin{array}{l}\text { For low bleeding risk } \rightarrow \text { extended anticoagulant } \\
\text { therapy }^{b}\end{array}$ & Grade IB \\
\hline & $\begin{array}{l}\text { For moderate bleeding risk } \rightarrow \text { extended } \\
\text { anticoagulant therapy }{ }^{\mathrm{b}}\end{array}$ & Grade 2B \\
\hline & For high bleeding risk $\rightarrow 3$ months & Grade 2B \\
\hline \multirow[t]{2}{*}{ DVT and active cancer } & $\begin{array}{l}\text { For low or moderate bleeding risk } \rightarrow \text { extended } \\
\text { anticoagulant therapy }\end{array}$ & Grade IB \\
\hline & $\begin{array}{l}\text { For high bleeding risk } \rightarrow \text { extended anticoagulant } \\
\text { therapy }^{b}\end{array}$ & Grade 2B \\
\hline
\end{tabular}

Notes: Initial and long-term therapy for PE is the same as for proximal DVT. Incidentally found asymptomatic DVT is suggested to be treated with initial and long-term anticoagulation as for comparable patients with symptomatic DVT (Grade 2B). alf decision has been made to treat with anticoagulant therapy; in patients who receive extended anticoagulant therapy, the continuing use of treatment should be reassessed at periodic intervals (eg, annually), patient preference considered, and the choice of anticoagulant regimen reevaluated.

Abbreviations: DVT, deep vein thrombosis; PE, pulmonary embolism.

It is important to make a distinction between acute therapy and secondary prophylaxis. In the acute phase, a minimal duration of anticoagulation is needed to prevent thrombus extension and embolism, and to ensure that the activated inflammatory and coagulation processes have returned to baseline. ${ }^{6}$ Beyond this required minimal duration of anticoagulation, secondary prophylaxis aims to prevent recurrent VTE, as even adequate anticoagulation during the acute phase cannot lower the risk of recurrence to the same level as in patients who have never had a VTE. Thus, anticoagulation does not cure VTE.?

The risk of recurrence of VTE after discontinuation of anticoagulation is primarily dependent on two factors. First, whether the acute VTE was treated effectively, including the minimally required duration of anticoagulation. Second, the presence of intrinsic risk factors that are known to promote recurrence, such as thrombophilia or malignancy.

There is a high probability of such intrinsic risk factors being present in patients with a first time episode of unprovoked proximal DVT, and in patients with recurrent unprovoked VTE, even if no such risk factor can be established at the time. Therefore, long-term anticoagulation is recommended in these cases.

But what does "long-term" mean? The ACCP Guidelines 5 suggest continuing anticoagulation until either the risk of recurrent VTE no longer clearly outweighs the increased risk of bleeding, or until the patient prefers to stop treatment, even if the weighing of risks and benefits would support continuation. As the risks vary greatly between individual patients, there is no universally recommended duration of anticoagulation beyond the minimally required one. Thus, the decision is left to the treating physician and the patient. Therefore, physicians need to have a good estimate of these risks in order to correctly weigh the risks and benefits. It is important to prevent recurrence of any type of VTE, but especially of fatal PE as worst outcome.

\section{Risk of bleeding}

Incidence of major bleeding while on anticoagulation varies among patient populations and across studies, but is estimated at $1 \%-4 \%$ per year with $0.4 \%-1.5 \%$ intracranial bleeding. Rates of major bleeding at 14,90 , and 180 days are $0.6 \%$, $1.0 \%$, and $1.1 \%$, respectively. The $14-$ and 30 -day case fatality rates after major bleeding are $8 \%$ and $25 \% .{ }^{8,9}$ Increased risk of bleeding has been associated with the following factors: Age $>65$ years, previous bleeding, cancer (metastatic or not), renal failure, liver failure, thrombocytopenia, previous stroke, diabetes, anemia, antiplatelet therapy, poor anticoagulant control, alcohol abuse, frequent falls, recent surgery, comorbidity, and reduced functional capacity. ${ }^{10}$ There are 
several scores to assess bleeding risk in patients with atrial fibrillation. HAS-BLED is an acronym for hypertension, abnormal renal/liver function, stroke, bleeding history or predisposition, labile international normalized ratio (INR), elderly, drugs/alcohol usage. ${ }^{11}$ Major bleeding is defined in the HAS-BLED study as intracranial, requiring hospitalization, decrease in hemoglobin of more than $2 \mathrm{~g} / \mathrm{L}$, and/or transfusion. Another score, the ATRIA (anticoagulation and risk factors in atrial fibrillation) study, used a five-variable risk score to predict warfarin-associated hemorrhage in a large community-based cohort of patients with atrial fibrillation. ${ }^{12}$ The HEMORR2HAGES-score also predicts bleeding in patients with atrial fibrillation. ${ }^{13}$ All three of these bleeding risk-estimation scores demonstrated only a modest performance in predicting clinically relevant bleeding. The HAS-BLED performed better than the ATRIA and HEMORR2HAGES scores, as reflected by the receiver operating characteristic (ROC) analysis. ${ }^{14}$ An additional scoring system, the RIETE score, was developed specifically for VTE patients, and is similar to the ATRIA score using recent bleeding, creatinine level, anemia, malignancy, symptomatic PE, and age as criteria. ${ }^{15}$ It was developed from a large cohort of patients, but has not yet been externally validated. All these scoring systems can be helpful to determine whether continuation of anticoagulation is in the best interest of VTE patients. The RIETE scoring system seems to be particularly useful as it is the only scoring system that is derived from a population of VTE patients. Its risk score is based on six variables that are easily assessed at initial diagnosis, and can identify VTE patients at low, intermediate, or high risk for major bleeding during the first 3 months of therapy.

\section{Prediction models for recurrent VTE}

Table 2 summarizes the risk ratio or hazard ratio (HR) of recurrent VTE. The Wells score allows probability calculation based on clinical factors for a first potential VTE event. But there are only a few scores for estimating VTE recurrence, and they are not as widely used as the Wells score.

One such score is the Vienna prediction model that assesses the recurrence in patients with unprovoked VTE. ${ }^{16}$ In this model, Eichinger et $\mathrm{al}^{16}$ use sex, location of first VTE event, and D-dimer after cessation of anticoagulation as predictive variables to estimate cumulative recurrence rates of VTE on a nomogram (Table 3). An update of the Vienna prediction model has been published, demonstrating the usefulness of D-dimer measurements at multiple random time points. By integrating these measurements into the
Table 2 Risk factors for venous thromboembolism recurrence given in relative risk/HR and its $95 \% \mathrm{Cl}$

\begin{tabular}{ll}
\hline Risk factor & $\begin{array}{l}\text { Relative risk/hazard } \\
\text { ratio }(95 \% \mathbf{C I})\end{array}$ \\
\hline Unprovoked proximal DVT $^{21}$ & $2.3(\mathrm{I} .8-2.9)$ \\
Obesity $^{28}$ & $1.6(\mathrm{I} . \mathrm{I}-2.4)$ \\
Male sex $^{30}$ & $2.8(\mathrm{I} .4-5.7)$ \\
Positive D-dimer testing $^{33}$ & $2.6(\mathrm{I} .9-3.5)$ \\
Residual thrombosis $^{36}$ & $1.5(\mathrm{I} . \mathrm{I}-2.0)$ \\
Hereditary thrombophilia $^{37}$ & $1.5(\mathrm{I} . \mathrm{I}-\mathrm{I.9})$ \\
Inflammatory bowel disease $^{40}$ & $2.5(\mathrm{I} .4-4.2)$ \\
Antiphospholipid antibody $^{41}$ & $2.4(\mathrm{I} .3-4.1)$ \\
Asian and Pacific Islander ethnicity & $0.7(0.5-0.9)$
\end{tabular}

Abbreviations: $\mathrm{Cl}$, confidence interval; DVT, deep vein thrombosis; HR, hazard ratio.

prediction model, it can now be used at any time from 3 weeks to 15 months after discontinuation of anticoagulation. ${ }^{17}$ Recently, the Vienna prediction model has been externally validated in 904 patients with unprovoked VTE. ${ }^{18}$ The ability of the Vienna prediction model to distinguish risk of VTE recurrence in the validation cohort was at least as good as in the original cohort, but a c-statistic of 0.63 (vs 0.65 in the original derivation cohort) was calculated. ${ }^{18}$ While the validation cohort could confirm the ability of the Vienna prediction model to stratify patients according to their risk of recurrence, a c-statistic - also known as ROC curve or area under curve (AUC) - of 0.63 is rather low and close to 0.5 , which would mean no power to predict recurrence.

The DASH prediction score uses similar risk factors such as elevated D-dimer after anticoagulation (2 points), age $\leq 50$ years ( 1 point), male sex ( 1 point), and - in women hormone use at the time of the initial VTE ( -2 points) to predict VTE recurrence in patients with previous unprovoked VTE (Table 3). ${ }^{19}$ The score was based on a patient-level meta-analysis of 1,818 patients with unprovoked VTE. The annual recurrence rate associated with DASH scores of -2 to 4 ranged from $1.8 \%$ per year to $19.9 \%$ per year. By considering a low recurrence risk (score below or equal to 1 ), long-term anticoagulation might be avoided in about half the patients with unprovoked VTE. ${ }^{19}$

The "Rodger" or "Men continue and HER DOO2" recurrent VTE risk assessment model identified those patients at low risk for recurrence who can safely discontinue anticoagulation therapy in a prospective cohort of 646 patients with unprovoked VTE. ${ }^{20}$ The overall annual risk of recurrence was $9.3 \%$ (95\% CI [confidence interval], 7.7\%-11.3\%). The annual risk of recurrent VTE was higher among men $(13 \% ; 95 \% \mathrm{CI}, 10.8 \%-17.0 \%)$ than women $(5.5 \% ; 95 \% \mathrm{CI}, 3.7 \%-7.8 \%)$. Men with signs 
Table 3 Prediction models for recurrent venous thromboembolism

\begin{tabular}{|c|c|c|c|}
\hline Model name & Vienna prediction model ${ }^{16}$ & DASH score ${ }^{19}$ & $\begin{array}{l}\text { Rodger or men continue and } \\
\text { HER DOO2 score }\end{array}$ \\
\hline Number of patients & 929 & $\mathrm{I}, 8 \mathrm{I} 8$ & 646 \\
\hline Design & Prospective cohort study & Patient-level meta-analysis & Prospective cohort study \\
\hline Predictive variables & $\begin{array}{l}\text { Male }>\text { female. } \mathrm{PE}>\text { proximal DVT }> \\
\text { distal DVT. Elevated D-dimer after AC }\end{array}$ & $\begin{array}{l}\text { D-dimer abnormal after cessation of } A C \\
\text { ( } 2 \text { points). Age } \leq 50 \text { years ( } I \text { point). } \\
\text { Sex - male (I point). Hormonal use at } \\
\text { VTE onset ( }-2 \text { points) }\end{array}$ & $\begin{array}{l}\text { Men continue. Hyperpigmentation } \\
\text { (I point). Edema (I point). Redness } \\
\text { (I point). D-dimer } \geq 250 \mu g / \mathrm{L} \\
\text { during AC (I point). Obesity } \\
\text { (BMI } \geq 30 \mathrm{~kg} / \mathrm{m}^{2} \text { ) (I point). } \\
\text { Old (age } \geq 65 \text { years) (I point) }\end{array}$ \\
\hline Total score & 0 to 350 & -2 to 4 & 0 to 6 \\
\hline Annual risk of recurrence & $\begin{array}{l}2 \%-15 \% \text { depending on total score } \\
\text { (nomogram) }\end{array}$ & $\begin{array}{l}\text { Score of } \leq \mathrm{I}: 3.1 \% \\
\text { Score of } 2: 6.4 \% \\
\text { Score of } \geq 3: 12.3 \%\end{array}$ & $\begin{array}{l}\text { Women with score of } \leq 1: 1.6 \% \\
\text { Women with score of } \geq 2: 14.1 \% \\
\text { Men: } 13.7 \%\end{array}$ \\
\hline
\end{tabular}

Abbreviations: DVT, deep vein thrombosis; VTE, venous thromboembolism; AC, anticoagulation; BMI, body mass index; PE, pulmonary embolism.

and symptoms of post-thrombotic syndrome (hyperpigmentation, edema, or redness in either leg) had a very high annual risk of recurrence (24\%). Women with two or more risk factors, namely post-thrombotic syndrome, D-dimer level of $\geq 250 \mu \mathrm{g} / \mathrm{L}$ during anticoagulation, body mass index (BMI) of $\geq 30 \mathrm{~kg} / \mathrm{m}^{2}$, or age of $\geq 65$ years, are at high risk for recurrent VTE and should thus continue anticoagulation. ${ }^{20}$ Women with 0 or 1 of these risk factors have a low annual risk of VTE recurrence (1.6\%) and can thus safely discontinue anticoagulation therapy. ${ }^{20}$ Unfortunately, in men no subgroup with low risk of VTE recurrence could be identified. All these risk prediction models are limited by the absence of a large prospective trial identifying the best model for risk stratification.

\section{Proximal and distal DVT and risk of recurrence}

Patients with an unprovoked VTE have a higher rate of recurrence after discontinuation of anticoagulation compared with those with a provoked VTE.

In a cohort study of 1,626 patients with provoked or unprovoked proximal DVT or PE, Prandoni et $\mathrm{al}^{21}$ could demonstrate that after discontinuation of anticoagulation and a median follow-up of 50 months, $22.3 \%$ of all patients had recurrence. Patients with an unprovoked first episode of VTE had the highest risk of recurrence with a HR of 2.3 (95\% CI, 1.8-2.9) compared with those with a provoked one. ${ }^{21}$ Isolated distal DVT refers to thrombosis of the infrapopliteal veins without concomitant thrombosis of the more proximal veins or PE. It represents half of all cases of lower limb DVT. In the prospective, observational, multicenter OPTIMEV study, the annual incidence of overall VTE recurrence was $2.7 \%$ (95\% CI, 1.9\%-3.8\%).
VTE events recurred more often in isolated proximal DVT than distal DVT with a HR of $1.8\left(95 \%\right.$ CI, 1.1-3.0). ${ }^{22}$. In a multivariate Cox proportional HR model, the authors found several predictive factors for recurrence after stopping anticoagulation in patients with isolated distal DVT. These factors were age over 50 years (HR, 3.7; 95\% CI, 1.0-10.6), unprovoked DVT (HR, 3.1; 95\% CI, 1.4-6.9), and multiple unilateral or bilateral DVT (HR, 2.9; 95\% CI, 1.4-6.1 and HR, 4.0; 95\% CI, 1.4-11.1, respectively). The annual risk of VTE recurrence was $3.8 \%$ (95\% CI, $0.3 \%-2.3 \%$ ) for age over 50 years, $3.8 \%$ (95\% CI, 2.6\%-5.6\%) for unprovoked distal DVT, $4.9 \%$ (95\% CI, 3.1\%-7.8\%) for multiple unilateral thrombosis, and $8.9 \%(95 \% \mathrm{CI}, 3.7 \%-21.4 \%)$ for bilateral DVT.22 Thus, whether distal DVT should be treated with anticoagulants at all is still a matter of debate. However, patients over the age of 50 with distal DVT that was unprovoked or involved several veins in one or both legs were found to be at significant risk for VTE recurrence. Thus, the threshold to treat these patients with anticoagulation therapy should be low.

DVT and PE are regarded as manifestations of the same disease, namely, VTE. It is unknown why some patients present with PE and others with symptomatic DVT alone. However, the initial presentation has an impact on the mode of VTE recurrence. Baglin et $\mathrm{al}^{23}$ showed in a patient-level meta-analysis that the 5-year rate of any VTE recurrence was $22 \%$ in patients initially presenting with $\mathrm{PE}$, and $26.4 \%$ in patients initially presenting with DVT. The risk of recurrence as PE was 3.1-fold greater in patients initially presenting with symptomatic PE than in patients with proximal DVT (HR, 3.1; 95\% CI, 1.9-5.1). ${ }^{23}$ Patients with proximal DVT had a 4.8-fold higher cumulative recurrence rate than those with distal DVT (HR, 4.8; 95\% CI, 2.1-11.0), as also seen in the prospective 
study by Galanaud et $\mathrm{al}^{22}$ and Baglin et $\mathrm{al}^{23}$ It is important to note for clinical care that patients with a first episode of PE are at the same risk for VTE recurrence as patients with DVT alone. However, PE patients are three times more likely to suffer another PE than a DVT as recurrence. Given the fact that the risk of fatal PE is two to four times greater in PE patients, the threshold of extending anticoagulation therapy beyond 3 months should be low in these patients.

Transient risk factors during the first episode of VTE such as major surgery, hospitalization for acute medical illness and trauma or fracture do not appear to raise the risk for recurrent VTE. ${ }^{24,25}$ However, a systematic review of prospective cohort studies and randomized trials of patients with a first episode of symptomatic VTE provoked by a transient risk factor and treated for at least 3 months showed - after stopping anticoagulation therapy - an annual recurrence rate of $3.3 \%$ per patient-year for all patients with a transient risk factor, $0.7 \%$ per patient-year in the subgroup with a surgical factor, and $4.2 \%$ per patient-year in the subgroup with a nonsurgical factor. ${ }^{26}$ In the same studies, the rate of recurrence after unprovoked VTE was $7.4 \%$ per patient-year. Thus, the presence or absence of a transient risk factor at the time of VTE strongly affects the risk of recurrence after anticoagulant therapy is stopped. The risk of recurrence is low if VTE is provoked by surgery, intermediate if provoked by a nonsurgical risk factor, and high if unprovoked. These risks should be considered when deciding on extending anticoagulation therapy. ${ }^{26}$

A family history ofVTE, meaning at least one first-degree family member affected by VTE, does not appear to raise the risk of recurrence. ${ }^{27}$

\section{Obesity and risk of VTE recurrence}

Increased BMI at the time of incident VTE seems to predict recurrence. ${ }^{2,7}$ In a large cohort study of 1,107 patients with VTE, Eichinger et $\mathrm{a}^{28}$ found that 4 years after discontinuation of anticoagulation therapy, the adjusted HR of recurrence was $1.3(95 \% \mathrm{CI}, 0.9-1.9)(P=0.20)$ among overweight patients and $1.6(95 \% \mathrm{CI}, 1.1-2.4)(P=0.02)$ among obese individuals compared with patients of normal weight. These data suggest that obesity is an important risk factor for recurrent VTE and should be taken into account when assessing the risk and benefit of anticoagulation therapy beyond 3 months.

\section{Male sex and risk of VTE recurrence}

Several studies have shown that risk of recurrence is higher in male patients. A meta-analysis of 15 studies (nine randomized controlled trials and six prospective observational studies) enrolling a total of 5,416 patients found a relative risk of recurrent VTE of 1.6 (95\% CI, 1.2-2) for men compared with women. ${ }^{29}$ In a prospective study of 474 patients with a first DVT, provoked or unprovoked, the risk of recurrence was $4.1 \%$ for men and $1.6 \%$ for women per person-year during a mean follow-up of 7.3 years (in total 3,477 personyears). ${ }^{30}$ Men with an unprovoked first event had a 2.8-fold higher risk for recurrence (95\% CI, 1.4-5.7) compared with women. ${ }^{30}$ Douketis et $\mathrm{al}^{31}$ found similar results in a more recent patient-level meta-analysis of 2,554 patients followed for 27 months. Among patients with unprovoked VTE, men were twofold more likely than women to suffer recurrent VTE (HR, 2.2; 95\% CI, 1.7-2.8). In contrast, there was no difference in recurrence risk between men and women after a first episode of provoked VTE (HR, 1.2; 95\% CI, 0.6-2.4). ${ }^{31}$ The reason for the increased risk in men remains unknown, but it seems clear that men and women do not share the same risk of recurrent VTE. Consequently, sex should be taken into account for risk stratification and prevention of VTE recurrence.

\section{Positive D-dimer testing following cessation of anticoagulation}

In patients who have elevated D-dimer levels 1 month after discontinuation of anticoagulation, the risk of recurrence is increased, as several studies have demonstrated. In a randomized controlled trial (PROLONG trial ${ }^{32}$ ), patients with unprovoked proximal DVT and positive D-dimer testing 1 month after discontinuation of anticoagulation therapy had a benefit if anticoagulation therapy was restarted. Six hundred and eight patients had received at least 3 months of anticoagulation before therapy was discontinued. After 1 month, D-dimers were assessed. In $36.8 \%$, testing was positive, and these patients were randomized to either restart anticoagulation therapy or have no further anticoagulation. During follow-up, $6.4 \%$ of patients who had had negative D-dimer testing developed recurrent VTE. Patients with positive D-dimer testing without continued anticoagulation had recurrence in $15 \%$, while those with positive D-dimer testing with continued anticoagulation had recurrence in $2.9 \%$, resulting in a HR of $4.3(95 \% \mathrm{CI}, 1.2-14.6){ }^{32}$

The results of the PROLONG trial were confirmed in a patient-level meta-analysis of seven prospective studies on D-dimer testing after cessation of anticoagulation therapy with a total of 1,818 patients with first unprovoked VTE. ${ }^{33}$ After a mean follow-up of 26.9 months, a multivariate Cox regression model, which included patient age, sex, hormone 
therapy at the time of the index event, BMI, timing of postanticoagulation D-dimer testing, and inherited thrombophilia as possible confounders, indicated that positive D-dimer testing was associated with a 2.6-fold higher risk of recurrence (95\% CI, 1.9-3.5). ${ }^{33}$

In a recent prospective cohort study of 410 adults aged 75 years or younger with a first unprovoked proximal DVT or PE who had completed 3-7 months of anticoagulation therapy, serial D-dimer testing was performed and anticoagulation therapy was not restarted if two D-dimer tests were negative. ${ }^{34}$ Rates of recurrent VTE during an average follow-up of 2.2 years were $6.7 \%$ (95\% CI, 4.8\%-9.0\%) per patient-year overall, 9.7\% (95\% CI, 6.7\%-13.7\%) per patient-year in men, and 5.4\% (95\% CI, 2.5\%-10.2\%) per patient-year in women with VTE not associated with estrogen therapy. ${ }^{34}$ Thus, the risk of VTE recurrence in patients with an unprovoked proximal VTE who have negative D-dimer is not low enough to justify stopping anticoagulation therapy in men, but may be low enough to justify stopping therapy in women. These results support the fact that male sex is an independent risk factor for VTE recurrence, and should be strongly considered in balancing risks and benefits of extending anticoagulation.

\section{Residual venous thrombosis and risk of VTE recurrence}

After an acute DVT, recanalization of the thrombosed vein takes time. In a study of 258 patients with proximal DVT, Siragusa et $\mathrm{a}^{35}$ demonstrated that after 3 months of anticoagulation therapy, there was residual thrombosis - defined as thrombosis of more than $40 \%$ of the vein diameter - in $69.8 \%$ of patients. Anticoagulation therapy was stopped in patients without residual thrombosis. Those patients with residual thrombosis were randomized to either stop therapy or continue anticoagulation (INR, 2.0-3.0) for 9 additional months. After a follow-up period of 2 years, patients without residual thrombosis at the beginning of the study had VTE recurrence and/or major bleeding in only $1.3 \%$, whereas recurrent events occurred in $27.2 \%$ of those patients with residual thrombosis who did not continue anticoagulation. The HR for patients with residual thrombosis and discontinued anticoagulation was 24.9 (95\% CI, 3.4-183.6) compared with patients without residual thrombosis. It should be noted that the CI was very wide as an indication of a certain imprecision of the data. ${ }^{35} \mathrm{~A}$ meta-analysis of 14 studies on residual thrombosis showed only a slight increase in risk of recurrence (HR, 1.5; $95 \%$ CI, 1.1-2.0). ${ }^{36}$

\section{Hereditary thrombophilia and risk of VTE recurrence}

In patients with mild thrombophilia, specifically heterozygous forms of Factor $V$ Leiden and prothrombin mutation, the relative risk of recurrent VTE is only slightly elevated at 1.5 (95\% CI, 1.1-1.9) and 1.4 (95\% CI, 1.0-1.8), respectively. As such, in the absence of other risk factors, an extended anticoagulation is not warranted based on mild thrombophilia alone. ${ }^{37}$ A Cochrane analysis, published in 2009, did not report any randomized controlled trials on use of thrombophilia screening to assess the risk of recurrence. ${ }^{38}$ An update in 2012 still could not find any data from controlled studies to support a recommendation on thrombophilia screening in this setting. ${ }^{39}$

\section{Inflammatory bowel disease and risk of VTE recurrence}

Inflammatory bowel disease (IBD) significantly increases the risk of a first VTE and also increases the risk of recurrence. In a prospective study of 2,811 patients with IBD compared to subjects without IBD it was demonstrated that the probability of recurrence 5 years after discontinuation of anticoagulation therapy was higher among patients with IBD than in those without $(33.4 \%$; 95\% CI, $21.8 \%-45.0 \%$ vs $21.7 \%$; $95 \%$ CI, $18.8 \%-24.6 \% ; P=0.01)$. After adjustment for potential confounders, IBD was an independent risk factor for recurrence (HR, 2.5; 95\% CI, 1.4-4.2; $P=0.001) .{ }^{40}$

\section{Antiphospholipid antibodies and risk of VTE recurrence}

Presence of antiphospholipid antibodies indicates a clearly elevated risk of recurrence of VTE. One hundred and sixty patients with antiphospholipid antibody syndrome who had previous venous or arterial thromboembolism were evaluated in a retrospective study by Pengo et al. ${ }^{41}$ The HR for recurrence after discontinuation of anticoagulation therapy was 2.4 (95\% CI, 1.3-4.1) compared with patients in whom therapy was continued. ${ }^{41}$

\section{Ethnicity and risk of VTE recurrence}

In a large epidemiologic study from California including more than 23,000 patients with provoked or unprovoked DVT, the incidence of recurrent VTE was analyzed in various subgroups. In patients of Asian or Pacific Islander ethnicity, the risk of recurrence was 0.7 times lower than in the Caucasian population (95\% CI, 0.5-0.9). ${ }^{42}$ Hispanic and African American ethnicity did not seem to have a higher risk of recurrent VTE 
(1.0 [95\% CI, 0.8-1.1] and 1.0 [95\% CI, 0.9-1.2], respectively) compared with the Caucasian population. ${ }^{42}$

\section{Malignancy and the risk of VTE recurrence}

The risk of recurrent VTE is increased two- to four-fold in patients with active cancer, and 4.2-fold for cancer patients undergoing chemotherapy., ${ }^{2,43}$

In a prospective cohort of 842 VTE patients on anticoagulant therapy with warfarin, including 181 with known cancer at inclusion, Prandoni et $\mathrm{al}^{43}$ noted a 12 -month cumulative incidence of recurrent thromboembolism of $20.7 \%(95 \%$ CI, $15.6 \%-25.8 \%$ ) among patients with cancer versus $6.8 \%$ (95\% CI, 3.9\%-9.7\%) in patients without cancer (HR, 3.2; 95\% CI, 1.9-5.4). Major bleeding was also more common among cancer patients and occurred in $12.4 \%$ (95\% CI, $6.5 \%-18.2 \%$ ) versus $4.9 \%(95 \% \mathrm{CI}, 2.5 \%-7.4 \%)$ in patients without cancer (HR, 2.2; 95\% CI, 1.2-4.1). ${ }^{43}$ Both VTE recurrence and bleeding were related to the severity of cancer, occurred predominantly during the 1 st month of anticoagulation, and were not associated with overanticoagulation. Thus, extended anticoagulation is recommended in patients with active cancer with or without chemotherapy. ${ }^{44-46}$

However, it seems that not all cancer patients have the same risk of VTE recurrence as shown in the Olmsted County cohort. Louzada et $\mathrm{al}^{47}$ performed a retrospective study on this population to develop a score and found, in a multivariate analysis, that female sex (1 point), lung cancer (1 point), and a history of previous VTE (1 point) were associated with an increased risk of recurrence. Breast cancer ( -1 point) and localized cancer disease (TNM stage 1) ( -2 points) were associated with a lower risk. Patients with a score of $\leq 0$ had low risk $(\leq 4.5 \%)$ of recurrence, and patients with a score of $\geq 1$ had a high risk ( $\geq 19 \%$ ) of VTE recurrence. Similar results were found by den Exter et $\mathrm{al}^{48}$ who validated the Ottawa prediction rule using a separate patient cohort. Lacking a prospective trial, the Ottawa prediction rule for recurrent VTE in cancer patients could be used to assess the risk of recurrence and in counseling patients on extension of anticoagulation therapy.

\section{Discussion}

Not all patients with VTE have the same risk of recurrence. Even patients with cancer seem to differ in their risk of VTE recurrence. Each of the individual risk factors described above is important to assess the risk of recurrent VTE, but on their own, none of them is specific enough to justify a general recommendation for the duration of anticoagulant therapy.
In most cases, a combination of risk factors needs to be considered to more accurately predict the recurrence risk, rather than one single risk factor. ${ }^{16}$

As an example, we discuss a male patient aged 59 who has received anticoagulation therapy for 3 months after an unprovoked proximal DVT. He has no other comorbidities. For how long should anticoagulation therapy as secondary prophylaxis be continued? The ACCP guidelines do not give a specific recommendation, as the decision needs to be based on the absolute risk of recurrence in the individual patient, and on the risk of bleeding complications. If we conservatively estimate the absolute risk of recurrence to be $2 \%-4 \%$ in this example, and assume a 2.8 -fold risk because of male sex, the risk increases to $6 \%-11 \%$ per year. If any other risk factors listed in Table 2 are present, the baseline risk should be multiplied by these HR to estimate risk of recurrence more precisely. In the example, an estimated recurrence risk of $6 \%-11 \%$ per year can be reason to continue anticoagulation, if the risk of major bleeding is low. In general, a risk of VTE recurrence of less than 3\% can be used to safely discontinue anticoagulation therapy. If the decision has been made to extend anticoagulation therapy, the risk of VTE recurrence decreases over time after the first event, and the risk of anticoagulant-related bleeding increases over time. Thus, the need for secondary prophylaxis must be regularly reassessed, again based on individual risk factors and on the resulting estimated risk of recurrent VTE. Secondary prophylaxis should be stopped if the benefit no longer exceeds the risk of bleeding.

If it is decided to discontinue anticoagulation after 3-12 months due to the risk assessment or because of patient preference, low-dose acetylsalicylic acid (ASA) can be considered for an additional 3 years. ${ }^{49}$ The ASPIRE $^{49}$ and WARFASA $^{50}$ trials were able to demonstrate a reduction in recurrent VTE of 32\% and a reduction of vascular events arterial and venous combined - of $34 \%$ without a significant increase in major bleedings. ${ }^{49,51}$

\section{Conclusion}

This review provides a comprehensive summary of important risk factors for recurrent VTE that need to be considered when planning treatment in the individual patient with VTE. It is no longer acceptable to simply recommend "life-long" or "indefinite" anticoagulation therapy, even in unprovoked proximal DVT or cancer, as not all patients have the same risk of recurrence. A personalized risk assessment and tailored anticoagulation therapy is essential to improve prevention of recurrent VTE. 


\section{Disclosure}

Dr Husmann has relationships with drug and device companies including Abbott Endovascular, Bard, Medtronic, EV3, Cordis, Sanofi Aventis, Daiichi Sankyo, Bayer, Boeringer Ingelheim, and AstraZeneca. In addition to being an investigator involved in endovascular and drug trials involving these companies, relationships include consultancy service, research grants, lecture honoraria, travel fees, and membership in advisory boards.

The other authors report no conflicts of interest in this work.

\section{References}

1. White RH. The epidemiology of venous thromboembolism. Circulation. 2003;107:I4-I8.

2. Heit JA, Mohr DN, Silverstein MD, et al. Predictors of recurrence after deep vein thrombosis and pulmonary embolism: a population-based cohort study. Arch Intern Med. 2000;160:761-768.

3. Christiansen SC, Cannegieter SC, Koster T, et al. Thrombophilia, clinical factors, and recurrent venous thrombotic events. JAMA. 2005; 293 : 2352-2361.

4. Kearon C, Kahn SR, Agnelli G, et al. Antithrombotic therapy for venous thromboembolic disease: American College of Chest Physicians Evidence-Based Clinical Practice Guidelines (8th Edition). Chest. 2008; 133:454S-545S

5. Guyatt GH, Akl EA, Crowther M, et al. Executive summary: antithrombotic therapy and prevention of thrombosis, 9th ed: American College of Chest Physicians Evidence-Based Clinical Practice Guidelines. Chest. 2012;141:7S-47S.

6. van Aken BE, den Heijer M, Bos GM, et al. Recurrent venous thrombosis and markers of inflammation. Thromb Haemost. 2000;83:536-539.

7. Boutitie F, Pinede L, Schulman S, et al. Influence of preceding length of anticoagulant treatment and initial presentation of venous thromboembolism on risk of recurrence after stopping treatment: analysis of individual participants' data from seven trials. BMJ. 2011;342:d3036.

8. White RH, Beyth RJ, Zhou H, et al. Major bleeding after hospitalization for deep-venous thrombosis. Am J Med. 1999;107:414-424.

9. Heit JA, Lahr BD, Petterson TM, et al. Heparin and warfarin anticoagulation intensity as predictors of recurrence after deep vein thrombosis or pulmonary embolism: a population-based cohort study. Blood. 2011; 118:4992-4999.

10. Kearon C, Akl EA, Comerota AJ, et al. Antithrombotic therapy for VTE disease: antithrombotic therapy and prevention of thrombosis, 9th ed: American College of Chest Physicians Evidence-Based Clinical Practice Guidelines. Chest. 2012;141:e419S-e494S.

11. Lip GY, Frison L, Halperin JL, et al. Comparative validation of a novel risk score for predicting bleeding risk in anticoagulated patients with atrial fibrillation: the HAS-BLED (Hypertension, Abnormal Renal/Liver Function, Stroke, Bleeding History or Predisposition, Labile INR, Elderly, Drugs/ Alcohol Concomitantly) score. J Am Coll Cardiol. 2011;57:173-180.

12. Fang MC, Go AS, Chang Y, et al. A new risk scheme to predict warfarinassociated hemorrhage: the ATRIA (Anticoagulation and Risk Factors in Atrial Fibrillation) Study. J Am Coll Cardiol. 2011;58:395-401.

13. Gage BF, Yan Y, Milligan PE, et al. Clinical classification schemes for predicting hemorrhage: results from the National Registry of Atrial Fibrillation (NRAF). Am Heart J. 2006;151:713-719.

14. Apostolakis S, Lane DA, Guo Y, et al. Performance of the HEMORR(2) HAGES, ATRIA, and HAS-BLED bleeding risk-prediction scores in patients with atrial fibrillation undergoing anticoagulation: the AMADEUS (evaluating the use of SR34006 compared to warfarin or acenocoumarol in patients with atrial fibrillation) study. $J$ Am Coll Cardiol. 2012;60:861-867.
15. Nieto JA, Solano R, Ruiz-Ribo MD, et al. Fatal bleeding in patients receiving anticoagulant therapy for venous thromboembolism: findings from the RIETE registry. J Thromb Haemost. 2010;8:1216-1222.

16. Eichinger S, Heinze G, Jandeck LM, et al. Risk assessment of recurrence in patients with unprovoked deep vein thrombosis or pulmonary embolism: the Vienna prediction model. Circulation. 2010;121:1630-1636.

17. Eichinger S, Heinze G, Kyrle PA. D-dimer levels over time and the risk of recurrent venous thromboembolism: an update of the Vienna prediction model. J Am Heart Assoc. 2014;3:e000467.

18. Marcucci M, Iorio A, Douketis JD, et al. Risk of recurrence after a first unprovoked venous thromboembolism: external validation of the Vienna Prediction Model with pooled individual patient data. JThromb Haemost. 2015;13(5):775-781.

19. Tosetto A, Iorio A, Marcucci M, et al. Predicting disease recurrence in patients with previous unprovoked venous thromboembolism: a proposed prediction score (DASH). J Thromb Haemost. 2012;10:1019-1025.

20. Rodger MA, Kahn SR, Wells PS, et al. Identifying unprovoked thromboembolism patients at low risk for recurrence who can discontinue anticoagulant therapy. CMAJ. 2008;179:417-426.

21. Prandoni P, Noventa F, Ghirarduzzi A, et al. The risk of recurrent venous thromboembolism after discontinuing anticoagulation in patients with acute proximal deep vein thrombosis or pulmonary embolism. A prospective cohort study in 1,626 patients. Haematologica. 2007; 92 : 199-205.

22. Galanaud JP, Sevestre MA, Genty C, et al. Incidence and predictors of venous thromboembolism recurrence after a first isolated distal deep vein thrombosis. J Thromb Haemost. 2014;12:436-443.

23. Baglin T, Douketis J, Tosetto A, et al. Does the clinical presentation and extent of venous thrombosis predict likelihood and type of recurrence? A patient-level meta-analysis. J Thromb Haemost. 2010;8:2436-2442.

24. Douketis JD, Foster GA, Crowther MA, et al. Clinical risk factors and timing of recurrent venous thromboembolism during the initial 3 months of anticoagulant therapy. Arch Intern Med. 2000;160: 3431-3436.

25. White RH, Murin S, Wun T, et al. Recurrent venous thromboembolism after surgery-provoked versus unprovoked thromboembolism. JThromb Haemost. 2010;8:987-997.

26. Iorio A, Kearon C, Filippucci E, et al. Risk of recurrence after a first episode of symptomatic venous thromboembolism provoked by a transient risk factor: a systematic review. Arch Intern Med. 2010;170:1710-1716.

27. Hron G, Eichinger S, Weltermann A, et al. Family history for venous thromboembolism and the risk for recurrence. Am J Med. 2006;119:50-53.

28. Eichinger S, Hron G, Bialonczyk C, et al. Overweight, obesity, and the risk of recurrent venous thromboembolism. Arch Intern Med. 2008; 168:1678-1683.

29. McRae S, Tran H, Schulman S, et al. Effect of patient's sex on risk of recurrent venous thromboembolism: a meta-analysis. Lancet. 2006; 368:371-378.

30. Christiansen SC, Lijfering WM, Helmerhorst FM, et al. Sex difference in risk of recurrent venous thrombosis and the risk profile for a second event. J Thromb Haemost. 2010;8:2159-2168.

31. Douketis J, Tosetto A, Marcucci M, et al. Risk of recurrence after venous thromboembolism in men and women: patient level meta-analysis. BMJ. 2011;342:d813.

32. Palareti G, Cosmi B, Legnani C, et al. D-dimer testing to determine the duration of anticoagulation therapy. N Engl J Med. 2006;355:1780-1789.

33. Douketis J, Tosetto A, Marcucci M, et al. Patient-level meta-analysis: effect of measurement timing, threshold, and patient age on ability of D-dimer testing to assess recurrence risk after unprovoked venous thromboembolism. Ann Intern Med. 2010;153:523-531.

34. Kearon C, Spencer FA, O'Keeffe D, et al. D-dimer testing to select patients with a first unprovoked venous thromboembolism who can stop anticoagulant therapy: a cohort study. Ann Intern Med. 2015; 162: 27-34.

35. Siragusa S, Malato A, Anastasio R, et al. Residual vein thrombosis to establish duration of anticoagulation after a first episode of deep vein thrombosis: the Duration of Anticoagulation based on Compression UltraSonography (DACUS) study. Blood. 2008;112:511-515. 
36. Carrier M, Rodger MA, Wells PS, et al. Residual vein obstruction to predict the risk of recurrent venous thromboembolism in patients with deep vein thrombosis: a systematic review and meta-analysis. JThromb Haemost. 2011;9:1119-1125.

37. Marchiori A, Mosena L, Prins MH, et al. The risk of recurrent venous thromboembolism among heterozygous carriers of factor $\mathrm{V}$ Leiden or prothrombin G20210A mutation. A systematic review of prospective studies. Haematologica. 2007;92:1107-1114.

38. Cohn D, Vansenne F, de Borgie C, et al. Thrombophilia testing for prevention of recurrent venous thromboembolism. Cochrane Database Syst Rev. 2009; 1:CD007069.

39. Cohn DM, Vansenne F, de Borgie CA, et al. Thrombophilia testing for prevention of recurrent venous thromboembolism. Cochrane Database Syst Rev. 2012;12:CD007069.

40. Novacek G, Weltermann A, Sobala A, et al. Inflammatory bowel disease is a risk factor for recurrent venous thromboembolism. Gastroenterology. 2010;139:779-787, 787. e1.

41. Pengo V, Ruffatti A, Legnani C, et al. Clinical course of high-risk patients diagnosed with antiphospholipid syndrome. JThromb Haemost. 2010;8:237-242.

42. White RH, Zhou H, Romano PS. Incidence of idiopathic deep venous thrombosis and secondary thromboembolism among ethnic groups in California. Ann Intern Med. 1998;128:737-740.

43. Prandoni P, Lensing AW, Piccioli A, et al. Recurrent venous thromboembolism and bleeding complications during anticoagulant treatment in patients with cancer and venous thrombosis. Blood. 2002;100:3484-3488
44. Lindhoff-Last E. Risk assessment of recurrence of venous thromboembolism. Hamostaseologie. 2011;31:7-12; quiz 13.

45. Akl EA, Barba M, Rohilla S, et al. Anticoagulation for the long term treatment of venous thromboembolism in patients with cancer. Cochrane Database Syst Rev. 2008;7:CD006650.

46. Lee AY, Levine MN, Baker RI, et al. Low-molecular-weight heparin versus a coumarin for the prevention of recurrent venous thromboembolism in patients with cancer. $N$ Engl J Med. 2003;349:146-153.

47. Louzada ML, Carrier M, Lazo-Langner A, et al. Development of a clinical prediction rule for risk stratification of recurrent venous thromboembolism in patients with cancer-associated venous thromboembolism. Circulation. 2012;126:448-454.

48. den Exter PL, Kooiman J, Huisman MV. Validation of the Ottawa prognostic score for the prediction of recurrent venous thromboembolism in patients with cancer-associated thrombosis. J Thromb Haemost. 2013;11:998-1000.

49. Brighton TA, Eikelboom JW, Mann K, et al. Low-dose aspirin for preventing recurrent venous thromboembolism. N Engl J Med. 2012;367: 1979-1987.

50. Becattini C, Agnelli G, Schenone A, et al. Aspirin for preventing the recurrence of venous thromboembolism. $N$ Engl J Med. 2012;366: 1959-1967.

51. Simes J, Becattini C, Agnelli G, et al. Aspirin for the prevention of recurrent venous thromboembolism: the INSPIRE collaboration. Circulation 2014;130(13):1062-1071.
Vascular Health and Risk Management

\section{Publish your work in this journal}

Vascular Health and Risk Management is an international, peerreviewed journal of therapeutics and risk management, focusing on concise rapid reporting of clinical studies on the processes involved in the maintenance of vascular health; the monitoring, prevention and treatment of vascular disease and its sequelae; and the involvement of

\section{Dovepress}

metabolic disorders, particularly diabetes. This journal is indexed on PubMed Central and MedLine. The manuscript management system is completely online and includes a very quick and fair peer-review system, which is all easy to use. Visit http://www.dovepress.com/ testimonials.php to read real quotes from published authors. 